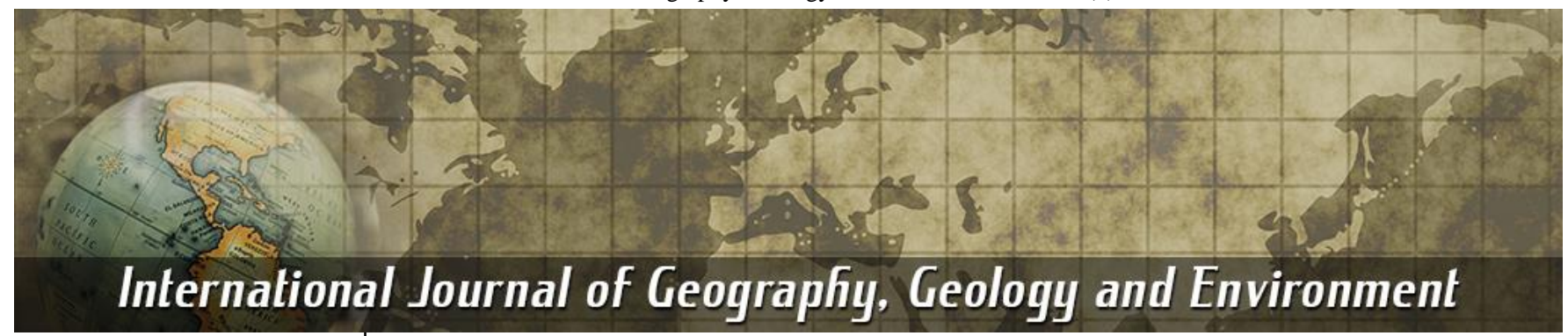

P-ISSN: 2706-7483 E-ISSN: 2706-7491 IJGGE 2021; 3(1): 26-28 Received: 11-11-2020 Accepted: 16-12-2020

\section{Meena Thakre}

Assistant Professor, Department of Geography, Gove College Bichhua, Chhindwara, Madhya Pradesh, India

Manita Kaur Virdi Assistant Professor, Department of Political Science, Government College Bichhua, Chhindwara, Madhya Pradesh, India
Corresponding Author: Meena Thakre Assistant Professor, Department of Geography, Gove College Bichhua, Chhindwara, Madhya Pradesh, India

\section{Role on Panchayti Raj institutions in environmental balance: Special study with reference to the state of Madhya Pradesh}

\section{Meena Thakre and Manita Kaur Virdi}

DOI: https://doi.org/10.22271/27067483.2021.v3.i1a.48

\begin{abstract}
Environmental Degradation or Environmental imbalance is becoming a serious problem of the world. In earlier times human population and technology knowledge were less due to which ecological exploitation was less. Hence the human environment relationship was balanced. But today due to increase in population technology efficiency, indoctrination, urbanization, rural-urban transfer, natural resources have been heavily exploited. As a result, many environmental problems such as the problem of pure water, forest destruction, exploitation of mining, smoke from transportation, industrial pollution etc.

Have adversely affected human health bio-diversity, climate change, and agricultural productivity. In such a situation, the contribution of Panchayti Raj Institution, the lowest level of administration for environmental protection, has been presented by researchers in this paper. The concept and development of Panchayti raj is ruled by five public representatives it is five representatives Brahmin, Kshatriya, Vishay, shudra and the fifth God. The $73^{\text {rd }}$ constitution amendment act of the Indian constitution provides Panchayti Raj institutions a wide right. Therefor the research paper presented has field study of environment related program in Madhya Pradesh. A vivid example of this can be seen as a contribution made by the Bhopal municipal corporation as a result of the 2december 1984 leak of methyl Isocyanine gas in Bhopal Madhya Pradesh.
\end{abstract}

Keywords: Environmental, Panchayti Raj

\section{Introduction}

Environment refers to a transition that affects the animal and plant community. The materialistic culture arising out of the Industrial revolution has created a crisis not only for the human community but also for the wild life, straying the human society. The threats posed by ecological imbalance are warning the entire human community for a movement. The factors responsible for this are urbanization, industrialization, expansion of means of transport, increase in population, competition of western civilization, biological destruction, jhuming farming, poverty and illiteracy, misuse of resource etc. presently, Panchayti in Madhya Pradesh state are discharging their role in planning and implementing development works by example, the Panchayti get information about the geographical location of the village under and prepare a plot of wasteland to prevent soil erosion by planting tree there. Several schemes and programs have been implemented in the Panchayti committees of Madhya Pradesh to balance the environment. Such as MNREGA Schemes, Swatch Bharat Abhiyan, Green Ganesh Scheme, Mukhyamantri Jal Swavalamban Abhiyan, Micro Irrigation Scheme, promotion of organic farming, Ujjwala Scheme etc. The researchers have also taken interviews of public representatives based on the data collected from various offices. During the interview, public representatives said that pollution in rural areas is caused by open defection, use of plastic, household fumes, dirty water, use of chemical fertilizers in agriculture, deforestation etc. So, these causes of environmental pollution are being solved by local institution.

\section{Study area}

The study area of the presented research paper is based on analysis of the role of Panchayti Raj Institution in environmental protection. 


\section{Objectives of the study}

1. Ensuring the need for environmental education and public awareness.

2. Promotion of forest protection and social forestry.

3. To motivate the villagers to plant trees around the vacant sites and fields of the village.

4. Panchayti Raj Institutions to increase per capita income by planting useful tree.

5. Proper exploitation and conservation of natural resources.

6. Promote the use of environmental friendly.

7. Providing incentives and protection to small and cottage industries.

8. Ensuring the role of local bodies for public participation.

\section{Methodology}

The library study method has been used in the research paper.

\section{Collection of data}

The research paper presented is based on primary and secondary data. The paper included facts from interviews of public representatives, information received from event arising out of changing geographical conditions, internet and news, current affairs of newspapers and magazines, library studies, publications of various institutions in India publications of state government etc. has gone.

\section{Analysis}

Local institutions have a huge role in resolving ecological imbalances. Today the whole earth is struggling with water scarcity. On the one hand, water use has intensified due to population growth and rapid industrialization, on the other hand these has been a decrease in rain water and an increase in excessive exploitation of ground water. In such a situation, judicious use of available water in the earth's surface has become extremely necessary. In this direction, the role of public institutions and public participation is very important. Bhind (Ater) is the district of Madhya Pradesh, which receives the least rainfall. The western part of Madhya Pradesh receives $31 \%$ more rainfall than the average while the 12 districts of the Chhindwara districts has received the lowest $54 \%$ rainfall so for, on the other hand, Asia's largest solar plant in Rewa of Madhya Pradesh was washed away due to floods. To deal with similar situations, a movement should be launched with local public support for water conservation. These ancient traditions of water conservation have to be revived by constructing ponds, step wells, jhalras, river-streams, lakes etc.

According to the report of the center for science and environment, if even half of the country's average rainwater is collected in the 1.12 hectares of land in each village, then there will be no water shortage in any village in the country. Different soil is found in different regions in terms of geographical division in Madhya Pradesh, in reaches the inner surface and some soil accumulates water in the upper surface only so that irrigation can work. Water from the roofs of house, water collected during the rainy period in ponds and rivers can be collected from the people of the village in deep pits by providing the employment. Apart from this, there is a need for movement for public awareness forwards environment protection so that rural people can get pure drinking water.
There is great need for forest protection and social forestry in the context of environment. Forest affects soil, climate, temperature, water level etc. In the atmosphere, while on the other hand they are helpful in keeping the air pure, raining preventing desertification, controlling floods. Social Forestry Program was adopted in the sixth five year plan under which emphasis was laid on wastelands, re- plantation and development of green belt/safety belt. Shady trees were planted in public places and along the roads.

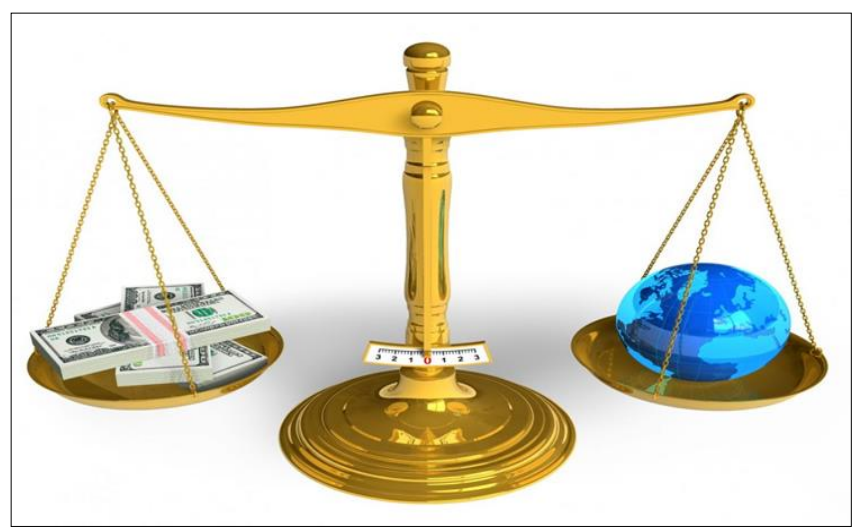

Fig 1: If the number of organisms and biomass is in a proper proportion at different trophic levels in a region, the environment in that region is said to be balanced. This balance can get disturbed due to natural hazards or by human intervention. Favorable ecosystem ensures that each organism thrive and multiply as expected. They get enough food to keep them alive. Ecological

balance is also important because it leads to the continuous existence of the organisms. It ensures that no particular species is exploited or overused.

It is necessary to pay attention to the presence of nutrients in the land by running a soil conservation program in land development. The fertility of land has been reduced due to the use of chemical fertilizers and pesticides, human health is also weakened. If farmer's use organic fertilizer, agricultural productivity will increase along with fertility. For this, earthworm fertilizer plants in rural areas can be prepared at a reasonable price, which will also provide employment to rural people. There is a great need for environmental protection, whose basis is the individual. Person, family, society, country, world are all part of nature. Man is incomplete without nature and without man is incomplete. Therefore, environmental management is necessary to improve the human-relationship. The "Narmada Bachao Andolan" of Medha Patkar, "Chipko Andolan" by Amrita Devi to protect the Khejri tree. Therefore, before starting the work globally, some work for environmental protection should be started at the local level. Instead to big irrigation projects, small irrigation projects should be developed, which will not harm the environment and will also provide irrigation facilities to the farmers. Presently, to tackle the energy crisis arising out of increasing energy consumption due to industrialization, socio-economic progress and traditional energy sources should be explored and used to conserve and renew energy sources. Currently Biogas plant should be used, which can be used as domestic fuel in rural areas. It is also environmental friendly.

Conclusion: for the protection and promotion of environmental, the local institutions should formulate policies for conservation of forest, water, wildlife and land 
implement them honesty with the co-operation of the local people. Local institution will also have to make necessary efforts for sustainable development of society. In a country like India, it is necessary to expand the role of local institutions for the development of environmental management. Through these institutions, the process of environmental protection can be speeded up but health problems can also be eliminated. Therefore, the new Panchayati Raj system is playing an important role in making the environment clean, pollution and green, under the responsibility of round development of the society.

\section{Suggestion}

1. Waste discharged from industries in villages and semiurban areas should be properly disposed of.

2. There should be proper exploitation of natural resources for sustainable socio-economic development.

3. Use of eco-friendly technology in consumer, commodity production.

4. Anti-pollution devices must be installed in factories.

5. The elderly, youth, children, woman should all be made aware of the environment.

\section{Reference}

1. Sharma Shrikamal. Geography of M.P., Madhya Pradesh Hindi Granth Academy.

2. Gurjer Ramkumar, Jat BC. Man and Environment. Panchsheel Prakashan, Jaipur 2002.

3. Narain Sunita. Parivartan Ki Ranjeet.

4. Bangda Parmeshwar. Environment Conservation and Panchayati Raj, Pratik Publication Jaipur. 